\title{
Knowledge, Attitude, Practice About Chemo Mechanical Caries Removal Method in Dental Caries Among Dentist in Chennai City- A Cross-Sectional Study
}

\author{
Amanthi Ganapathi ${ }^{1}$ and Jayashri Prabakar ${ }^{2}$ \\ ${ }^{1}$ Saveetha Dental college \& Hospitals, Saveetha Institute of Medical and \\ Technical Sciences, Saveetha University, Chennai, India \\ ${ }^{2}$ Senior Lecturer, Department of Public Health Dentistry Saveetha Dental College \&t Hospitals, \\ Saveetha Institute of Medical and Technical Sciences, Saveetha University, Chennai, India
}

\section{ABSTRACT}

Minimally Invasive Dentistry (MID) emphasizes conservative caries management strategies resulting in less destruction of tooth structure, a deviation of the traditional GV Black's restorative principles. However, there seems to be either deficiency in knowledge or little intention by general dental practitioners to adopt these principles.The aim of this study was to assess the knowledge and attitude among general dental practitioners towards minimally invasive dentistry in Chennai.The study was conducted through an online survey among the dentists. A structured and self administered questionnaire was adapted from questionnaires used previously in studies done by Schwendicke et al (Schwendicke et al., 2013).The questions assessed the respondents' levels of agreement regarding diagnostic, preventive and restorative techniques, types of caries removable agents, Atraumatic Restorative.The Chi-Square test was applied to assess the association between level of education and responses. In our study it showed that most of the dentists who took part were male dentists, $42 \%$ of the participants had no awareness regarding CMCR,58\% which is the majority of the participants did not have awareness regarding CMCR..75\% of the participants were interested in taking part in a CDE programme on CMCR. It was found that MDS graduates had significantly higher knowledge regarding the chemo mechanical agents but clinical usage was comparatively lesser.The curriculum plays an important role in chemo mechanical caries removal agent needs to be determined precisely and clearly.

KEY WORDS: CHEMOMECHANICAL CARIES REMOVAL SYSTEM (CMCR),CARIDEX, CARISOLV, PAPACARIE, SURVEY.

\section{INTRODUCTION}

The approach for deep dentin caries management has always been an riddle for the restorative dentist. The old attempt was to eradicate bacteria and all infected dental

\section{ARTICLE INFORMATION}

${ }^{*}$ Corresponding Author: jayashri.sdc@saveetha.com Received 5th Aug 2020 Accepted after revision 26th Sep 2020 Print ISSN: 0974-6455 Online ISSN: 2321-4007 CODEN: BBRCBA

Thomson Reuters ISI Web of Science Clarivate Analytics USA and Crossref Indexed Journal

\section{Clarivate
Analytics}

NAAS Journal Score 2020 (4.31) SJIF: 2020 (7.728)

A Society of Science and Nature Publication,

Bhopal India 2020. All rights reserved.

Online Contents Available at: http//www.bbrc.in/

Doi: http://dx.doi.org/10.21786/bbrc/13.8/172 biomass and subsequent restoration has been debated by new philosophers who have contemplated the benefits of avoiding the potential complications of complete excavation of carious dentin close to the pulp. There is growing evidence supporting the incomplete removal of carious tissue before the cavity is restored(Banerjee, Watson and Kidd, 2000). Suppositionally, it is argued that a completely sealed remaining caries lesion should be arrested. Hence, therapy of cavitated lesions may require less focus on complete excavation than on adequate restorations(Ricketts, 2001; Kidd, 2004).From time immemorial, dentists have removed all infected enamel and dentin using excavators or high- and low-speed instruments, and thereby risking exposure of the pulp. Instead of attempting to remove all bacteria, it should be 
sufficient to re-shift the ecologic and Metabolic balance within the biofilm, thus promoting re-mineralization, thereby arresting the caries lesions(Bjorndal and Kidd, 2005).

The primary focus in the minimally invasive dentistry of caries management is identifying and eliminating the causative agent, along with repairing the damages which have been caused by the organism (Banerjee and Doméjean, 2013). Dental caries is now viewed as an infection rather than as a lesion and its treatment protocol is to reduce or eliminate pathogens contents in the teeth; this can be viewed as a retrieval from the traditional restorative treatment (Frencken et al., 2012). The minimally invasive dentistry symbolises knowledge of the disease process and simple concepts on new technologies (Uskokovi $\rrbracket$ and Bertassoni, 2010). The minimally invasive dentistry cares to address the early carious lesion and the causes of the disease process and also emphasizes on conservation of tooth structure , which is a deviation from the traditional GV Black's restorative principles (Wolff, Allen and Kaim, 2007). In contrast to traditional methods, this philosophy has allowed control of dental caries via prevention and conservation of tooth structure through conservative cavity preparations, adhesive materials and evidencebased decision-making (Tyas et al., 2000).

One of the most common problems in clinical dentistry is how to minimize the use of drills to overcome fear and have a patient friendly approach. Chemomechanical caries removal system is one of the theories that have changed the perception of dental treatment, making it more patient friendly. This amounts to instill a positive dental attitude, which in turn reduces the efforts of pediatric dentists to imply behavior management techniques and achieve child's cooperation easily. On the other hand, pediatric Dentist's all around, have conceptualized the importance of preserving tooth tissue combined with a patient-friendly approach, which is becoming selfevident. This has led to revolutionize Dentistry with the concept of 'minimal invasive dentistry'. Minimal invasive dentistry comprises various techniques, viz; air abrasion, atraumatic restorative technique, sono abrasion, laser and chemomechanical caries removal system (CMCR) (Kavvadia et al., 2004; Ganesh and Parikh, 2011). Thus,CMCR can be designated as a minimally invasive, painless and patient friendly technique, recommended for pediatric dental patients(Ganesh and Parikh, 2011);(Munshi, Hegde and Shetty, 2001; Kavvadia et al., 2004; Balciuniene, Sabalaite and Juskiene, 2005).

Chemomechanical caries removal technique involves the application of chemical agents, to cause a selective softening of the carious dentine and facilitates removal by gentle excavation. Since, its inception in 1980's, CMCR has been originally marketed as 3 different systems, viz, Caridex,Carisolv ${ }^{\circledR}$ and Papacarie ${ }^{\circledR}$ (Bussadori, Castro and Galvão, 2006; Corrêa et al., 2007) Caridex required large volumes of solution and a special applicator tip, which weaned its popularity around 1990's and thus, was discontinued to be marketed(Beeley, Yip and Stevenson,
2000). Carisolv ${ }^{\circledR}$ and Papacarie ${ }^{\circledR}$ were later introduced around 2000, which had overcome the limitations of Caridex and are being used among clinicians aware of this technique. The Carisolv ${ }^{\circledR}$ system uses a gel and special instruments that removes the pathologically affected portion of the tooth structure and preserves the healthy tissue. Papacarie ${ }^{\circledR}$ is based on a similar system as the latter but does not include special instruments for caries removal and is relatively cheap[16]. Both systems have been proved to be effective in caries removal(Corrêa et al., 2007).However, high cost is a limiting factor to daily use in developing and under- developed countries(Corrêa et al., 2008).

India is one of the developing countries. Since, the popularity of any system depends upon its economic viability, under-developed and developing countries find it difficult to incorporate an expensive mode of treatment. As mentioned previously, CMCR includes high cost, due to which its popularity in a developing country like India is insufficient. Although an expensive mode of treatment, CMCR being an effective technique for pediatric and special children. Hence, this study was carried out to determine the awareness of CMCR among clinicians in chennai, which if not present can be incorporated through continuing dental education programs and marketing.We have successfully completed numerous epidemiological studies for the betterment of our community (Prabakar, John, Arumugham, Kumar and Sakthi, 2018a, 2018b; Prabakar, John, Arumugham, Kumar and Srisakthi, 2018; Vishnu Prasad et al., 2018; Khatri et al., 2019; Manchery et al., 2019; Shenoy, Salam and Varghese, 2019). In this research we are studying the Knowledge, attitude, practice about chemo mechanical caries removal agents among dentists in chennai city.

\section{MATERIAL AND METHODS}

Study Design: The present study is a cross-sectional study.

\section{Study area: Saveetha Dental college}

Sample size: $N=200$ (95\% power @ 5\% alpha). Sample size was calculated based on the study done by Schwendicke et al., 2013

Sampling technique: Convenience sampling technique.

Ethical Approval: The ethical approval was passed by the Institutional ethical committee,Saveetha Dental college \& Hospitals Saveetha Institute of medical and Technical science,Saveetha University.

Data collection and Survey Instrument: The study was conducted through an online survey among the dentists. A structured and self administered questionnaire was adapted from questionnaires used previously in studies done by Schwendicke et al (Schwendicke et al., 2013). The survey tool consisted of several parts. The first section collected demographic information of the participants such as age, gender, highest level of education and 
number of years of experience in clinical practice. The second part of the questionnaire consisted of 14 questions to assess the participant's levels of knowledge and attitude and practices regarding Chemico-mechanical caries removal method in dental caries.

Data Analysis: Only completely filled forms were considered for analysis. Data was analyzed using the Statistical Package for Social Sciences (SPSS Chicago, Illinois,USA).Frequency distribution were carried out for all variables.The Chi-Square test was applied to assess the significance of differences between groups at a $\mathrm{p}$-value of 0.05 .

Figure 1: Bar chart represents the distribution of study subjects based on gender. $\mathrm{X}$ axis denotes the gender of the participants and $\mathrm{Y}$ axis denotes number of participants(Percentage). $47 \%$ of the study population were females and 53\% of the study population were male.

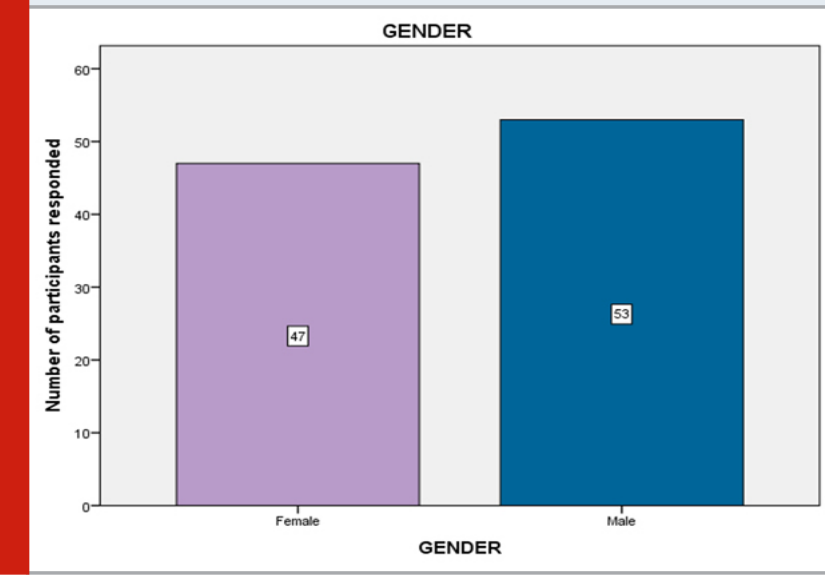

RESULTS AND DISCUSSION

In our study the distribution of study subjects based on gender. $47 \%$ of the study population were females and $53 \%$ of the study population were male is shown in figure-1.The distribution of study subjects based on age. 4\% of the study population were 23-30 years old and 5\% of the study population were $31-40$ years old,91\% were 41 and above is shown in figure-2.The distribution of study subjects based on the highest level of education.60.5\% participants completed BDS and $39.5 \%$ of the participants completed MDS.is shown in figure-3.The distribution of study subjects based on the years of clinical practice. $4 \%$ of the participants had less than 5 years of clinical practice, $5 \%$ of the participants had 5-10 years of clinical practice, $91 \%$ of the participants had more than 10 years of clinical practice is shown in figure-4.Figure 5 shows the distribution of study subjects based on their awareness regarding the CMCR. $42 \%$ of the participants had no awareness regarding CMCR,58\% which is the majority of the participants did not have awareness regarding CMCR.

Figure 6 shows the distribution of study subjects based on their clinical practice with the CMCR.24\% of the participants used CMCR in their clinical practice,76\% of the participants did not use CMCR in their clinical practice. Figure 7 represents the distribution of study subjects regarding the CMCR working method. 15\% of the participants know how CMCR works,65\% of the participants do not know how CMCR works.Figure 8 represents the distribution of study subjects regarding their knowledge on which dentition CMCR is used.

Figure 2: Bar chart represents the distribution of study subjects based on age. $\mathrm{X}$ axis denotes the age of the participants and $\mathrm{Y}$ axis denotes number of participants responded (Percentage). 4\% of the study population were 23-30 years old(Green) and 5\% of the study population were 31-40 years old(Light blue),91\% were 41 and above(Dark blue).

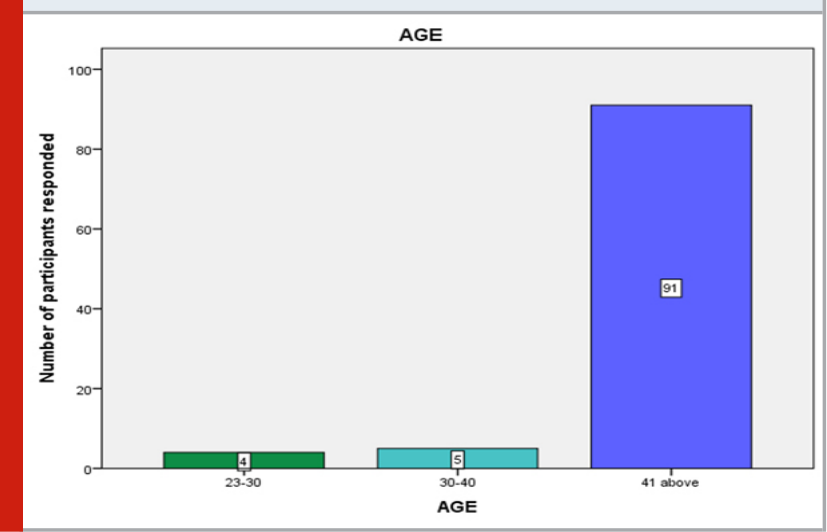

Figure 3: Bar chart represents the distribution of study subjects based on the highest level of education.X axis represents the participants highest level of education.Y axis shows the number of participants responded.60.5\% participants completed BDS and 39.5\% of the participants completed MDS.

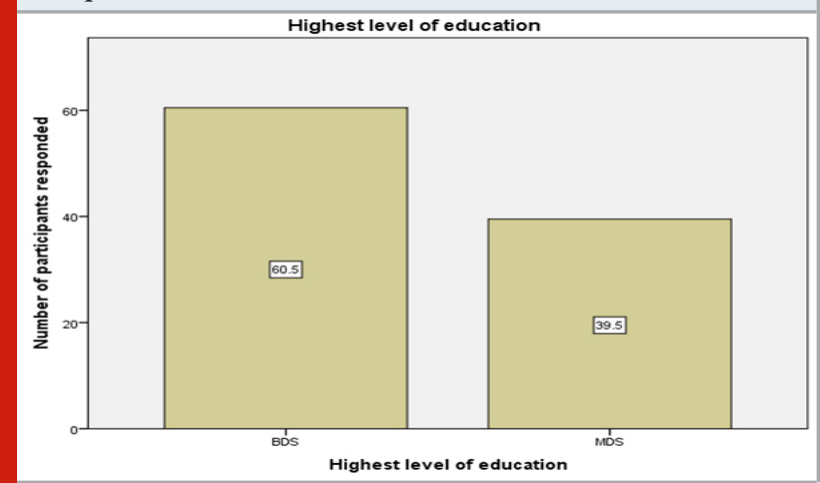

$10 \%$ of the participants believe CMCR is used in primary dentition, 24\% of the participants believe CMCR is used in permanent dentition, $17 \%$ of the participants believe CMCR is used in both dentitions, $48 \%$ of the participants do not know. Figure 9 represents the distribution of study subjects regarding their knowledge on different types of caries removal agents.46\% answered air abrasion, 29.5\% answered sono abrasion, 17\% answered CMCR,2.5\% answered laser abrasion,5\% answered ART.Figure 10 represents the distribution of study subjects regarding 
their knowledge on different types of CMCR...3\% answered cariodex,29.5\% answered carisolv,8.5\% answered papacarie, $1.5 \%$ answered biosol,57.5\% answered none which accounts more when compared to others.

Figure 4: Bar chart represents the distribution of study subjects based on the years of clinical practice. $\mathrm{X}$ axis represents the years of clinical practice..Y axis shows the number of participants responded. $4 \%$ of the participants had less than 5 years of clinical practice, $5 \%$ of the participants had 5-10 years of clinical practice, $91 \%$ of the participants had more than 10 years of clinical practice.

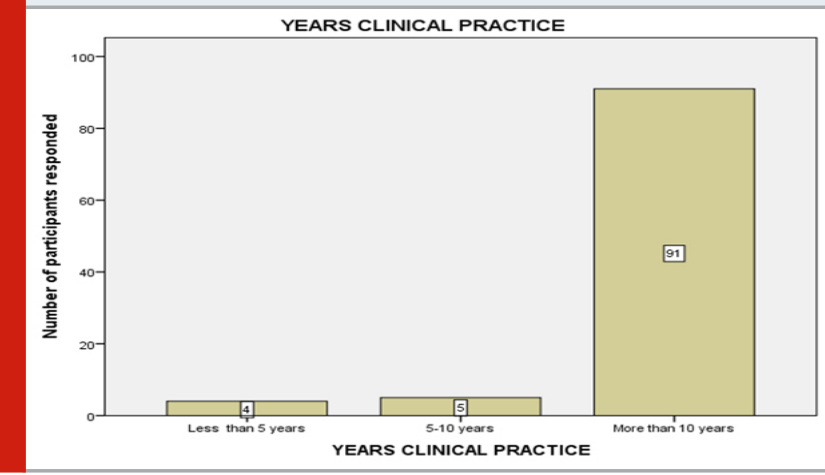

Figure 6: Bar chart represents the distribution of study subjects based on their clinical practice with the CMCR.X axis representing do you use CMCR in your clinical practice. $\mathrm{Y}$ axis shows the number of participants responded. $24 \%$ of the participants used CMCR in their clinical practice, $76 \%$ of the participants did not use CMCR in their clinical practice.

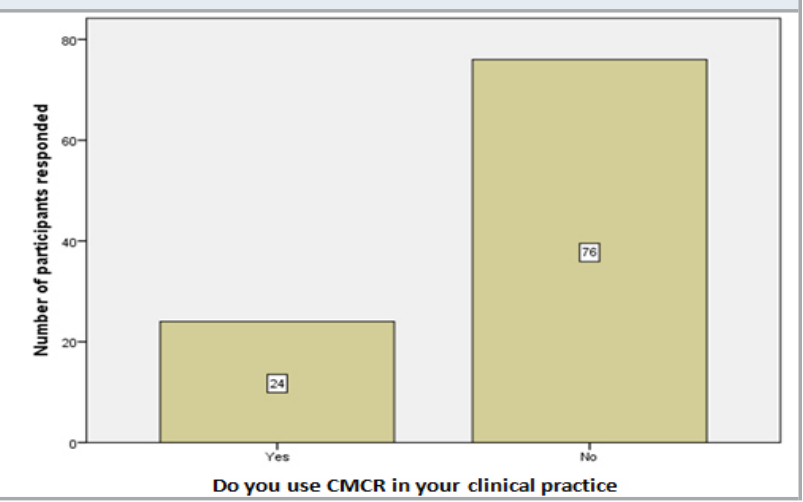

Figure 11 represents the distribution of study subjects regarding their knowledge on different combination of CMCR.10.5\% answered cariodex and carisolv,27\% answered carisolv and papacarie, $6 \%$ answered cariodex and papacarie,56.5\% answered none which accounts more when compared to others.Figure 12 represents the distribution of study subjects regarding the reason for choosing CMCR.20.5\% answered convenience for disable patients, $31 \%$ answered easy to use in difficult to control children, $17.5 \%$ answered facilitates ease in anxious patients, $17.5 \%$ answered because of minimally invasive, $13.5 \%$ answered because no need to use
Figure 5: Bar chart represents the distribution of study subjects based on their awareness regarding the CMCR.X axis represents the awareness about CMCR. .Y axis shows the number of participants responded. $42 \%$ of the participants had no awareness regarding CMCR,58\% which is the majority of the participants did not have awareness regarding CMCR.

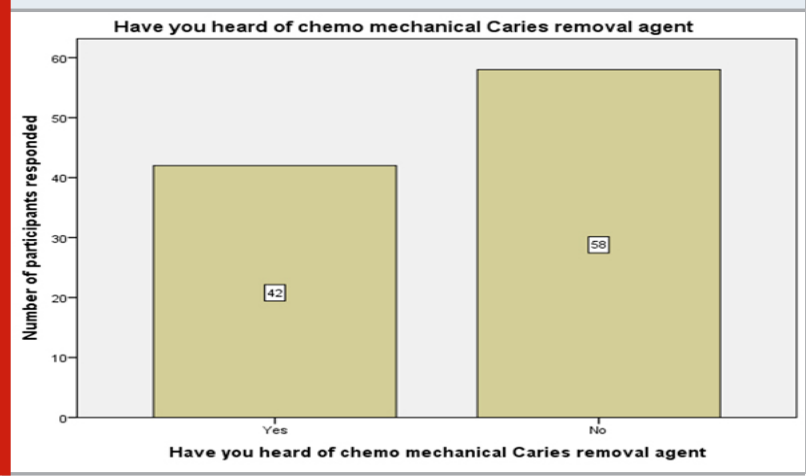

Figure 7: Bar chart represents the distribution of study subjects regarding the $\mathrm{CMCR}$ working method. $\mathrm{X}$ axis representing do you know how CMCR agent works.Y axis shows the number of participants responded. 15\% of the participants know how CMCR works, $65 \%$ of the participants do not know how CMCR works.

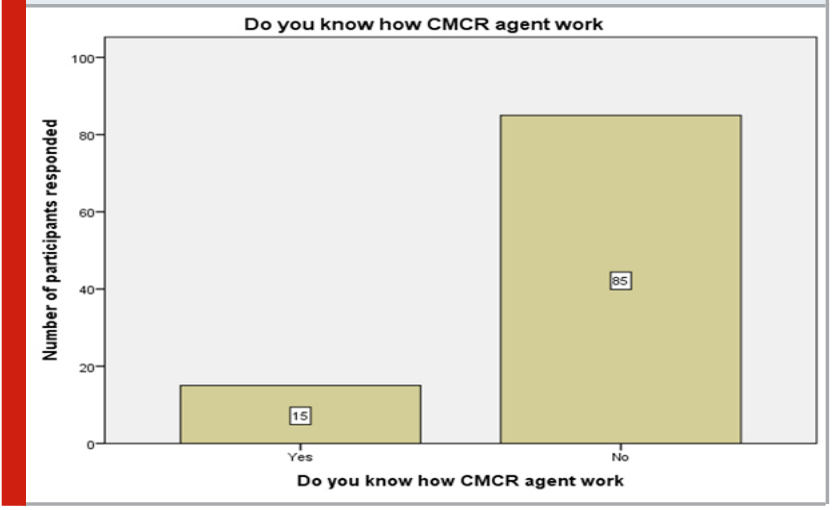

anesthesia.Figure 13 represents the distribution of study subjects regarding their interest in taking part in CDE programme.75\% of the participants answered yes and $25 \%$ of the participants answered no.The association between levels of education and responses to the questions. A statistically significant association was observed using Chi-square test $(\mathrm{p}<0.05)$. Hence proving Post graduates exhibited higher level of Knowledge and attitude towards chemo-mechanical removal method for caries removal when compared to undergraduates.

In the current scenario, different treatment modalities have been introduced for the removal of carious tissue while maintaining the maximal preservation of the healthy dental structure. The development of caries removal techniques in pediatric dentistry is aiming toward a more biological and conservative direction(ten Berge et al., 1999).The chemical-mechanical method of 
caries removal became a new arena in the dental research field due its concept of tissue preservation. As only infected dentin is removed, the painful removal of sound dentin is avoided. Hence, a painless technique is one of the keys to avoid dentally fearful and uncooperative children, and a skill every pediatric dentist should strive to master(Kotb et al., 2009).

Figure 8: Bar chart represents the distribution of study subjects regarding their knowledge on which dentition CMCR is used.X axis represents in which type of dentition CMCR is used.Y axis shows the number of participants responded. $10 \%$ of the participants believe CMCR is used in primary dentition, $24 \%$ of the participants believe CMCR is used in permanent dentition, $17 \%$ of the participants believe CMCR is used in both dentitions, $48 \%$ of the participants do not know.

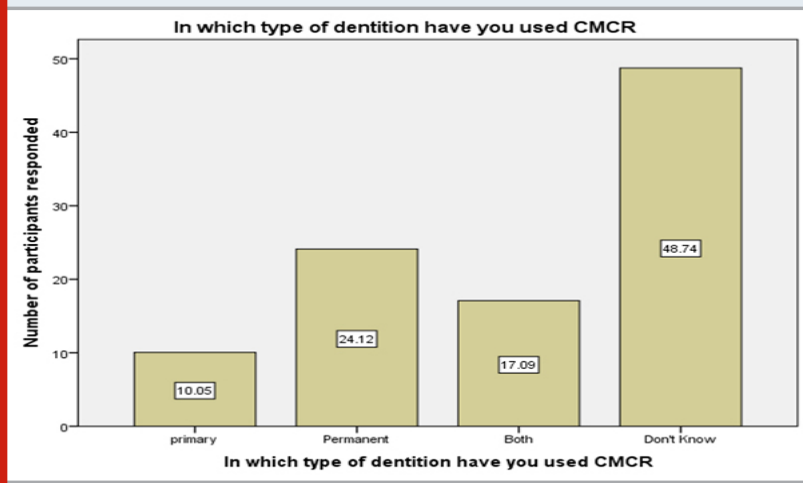

Figure 10: Bar chart represents the distribution of study subjects regarding their knowledge on different types of CMCR.X axis represents what are the CMCR agents you know.Y axis shows the number of participants responded.3\% answered cariodex,29.5\% answered carisolv, 8.5\% answered papacarie, $1.5 \%$ answered biosol,57.5\% answered none which accounts more when compared to others.

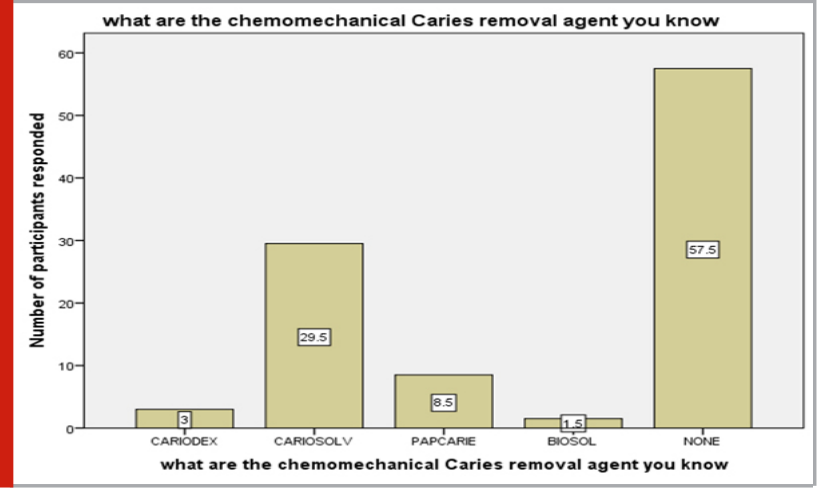

The purpose of this study was to investigate whether there was any difference in the level of knowledge and education about the chemomechanical caries removal method among the dentists or newly graduated dentists trained in chennai city. The majority of participants were still in training. The participants with 40 years and above of age had the biggest contribution with
Figure 9: Bar chart represents the distribution of study subjects regarding their knowledge on different types of caries removal agents. $\mathrm{X}$ axis represents what other treatment modalities are used for caries removal agent.Y axis shows the number of participants responded.46\% answered air abrasion, 29.5\% answered sono abrasion, 17\% answered CMCR,2.5\% answered laser abrasion,5\% answered ART.

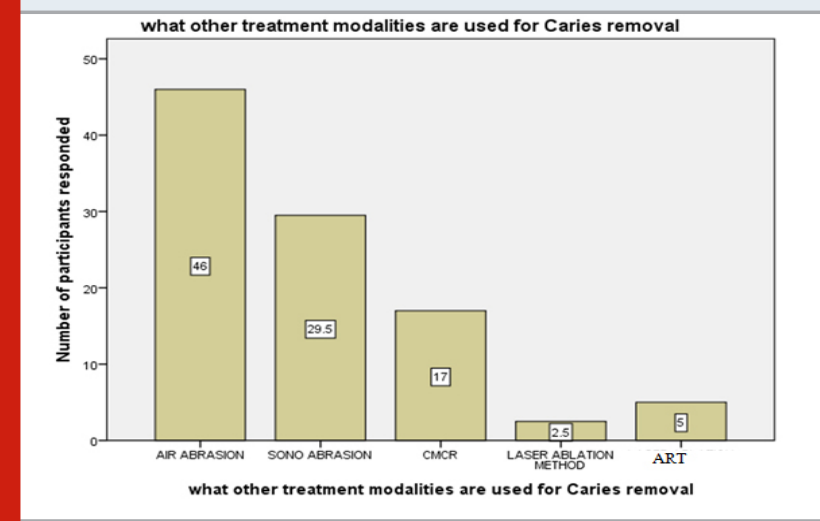

Figure 11: Bar chart represents the distribution of study subjects regarding their knowledge on different combination of CMCR.X axis represents what are the combination of CMCR agents you know.Y axis shows the number of participants responded.10.5\% answered cariodex and carisolv,27\% answered carisolv and papacarie,6\% answered cariodex and papacarie,56.5\% answered none which accounts more when compared to others.

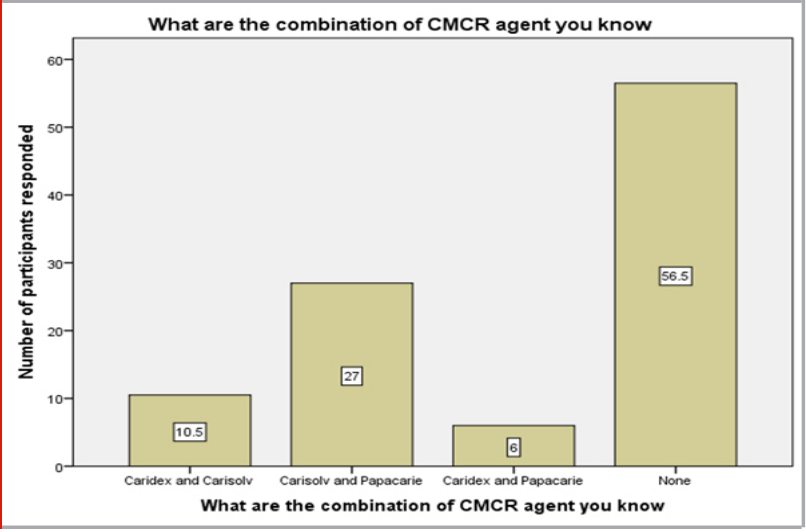

91\%. In addition, the majority of participants were men. The main point of interest in this study is that the majority of practitioners participating in the study were eager to learn these methods through courses. From this point, it can be argued that it may be necessary to give more time to teach these methods at the level of undergraduate education.

In a study conducted in the USA and Canada, it was reported that the dentistry curriculum does not cover CMCR products, and in the USA and Canada dental medicine graduates reported that they did not have enough knowledge about CMCR products(Scrabeck and 
List, 1989).In Turkey, CMCR method and products are in the scope of dentistry curriculum and 13.8\%(Baglar and Avunduk, 2018).In India, 14.3\% of the participants in Pune city reported that have knowledge about Caridex,57.1\% of about Carisolv and 28.6\% of them have knowledge about Papacarie. In Mumbai city, 25\% of the participants have information about Caridex, 75\% of them about Carisolv, and none of the participants in this city have any information about the Papacarie method were as in our present study showed that $3 \%$ answered cariodex,29.5\% answered carisolv, $8.5 \%$ answered papacarie, 1.5\% answered biosol,57.5\% answered none (Bijle et al., 2013). The ignorance of the new systems has led to the need to follow current studies and transfer these developments to curriculum content.At this point, it is necessary to standardize the course divided into the curriculum and the course content should be put into a certain level.

Figure 12: Bar chart represents the distribution of study subjects regarding the reason for choosing CMCR.X axis represents what do you think is the reason for choosing CMCR system.Y axis shows the number of participants responded.20.5\% answered convenience for disable patients, $31 \%$ answered easy to use in difficult to control children, $17.5 \%$ answered facilitates ease in anxious patients, $17.5 \%$ answered because of minimally invasive, $13.5 \%$ answered because no need to use anesthesia.

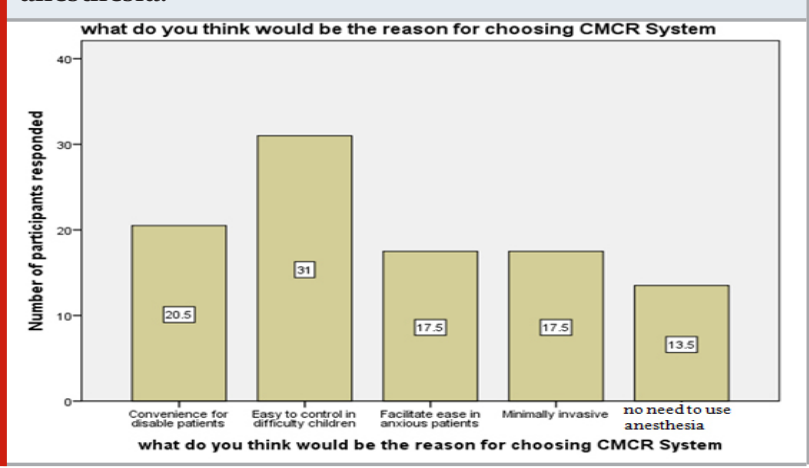

Figure 13:Bar chart represents the distribution of study subjects regarding the reason for not choosing CMCR.X axis represents what do you think is the reason for not choosing CMCR system.Y axis shows the number of participants responded.19.5\% answered not having enough information, 35\% answered time consumption,30\% answered expensive, $15.5 \%$ answered inadequate method /technique sensitive.

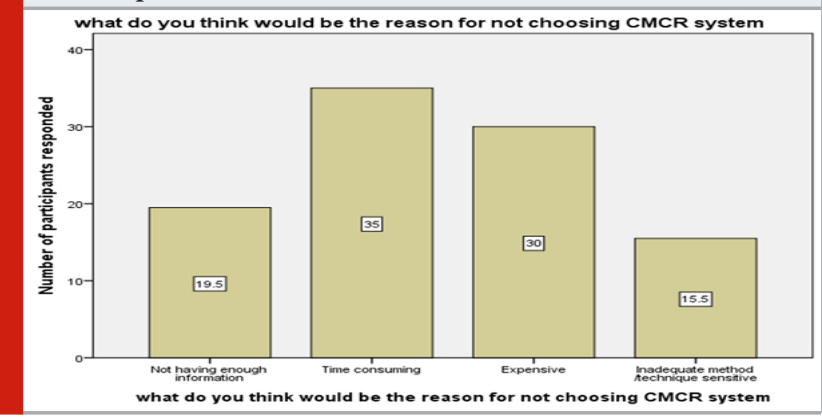

Figure 14: Bar chart represents the distribution of study subjects regarding their interest in taking part in CDE programme. $X$ axis represents are you interested in taking part in CDE on CMCR.Y axis shows the number of participants responded.75\% of the participants answered yes and $25 \%$ of the participants answered no.

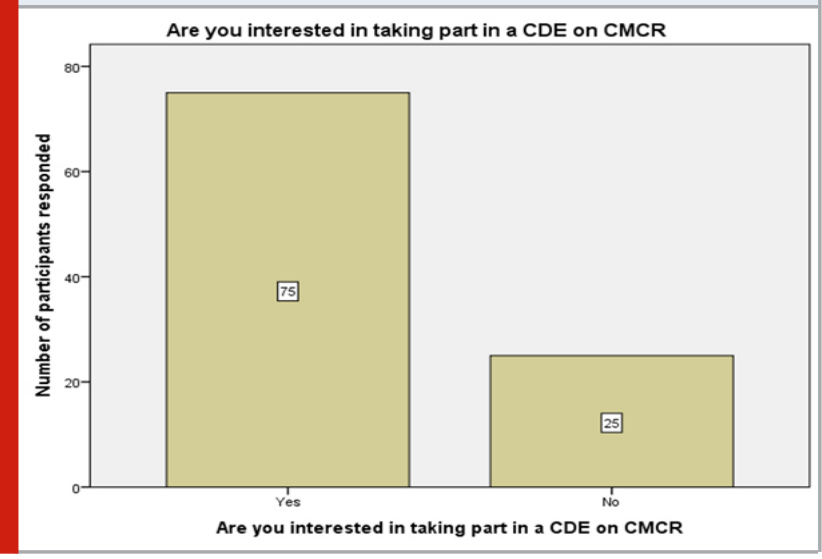

Table 1. Shows the association between levels of education and responses to the questions. A statistically significant association was observed using Chi-square test $(\mathrm{p}<0.05)$. Hence proving Post graduates exhibited higher level of Knowledge and attitude towards chemo-mechanical removal method for caries removal when compared to undergraduates.

\begin{tabular}{|l|c|c|c|c|c|}
\hline \multirow{2}{*}{ QUESTIONS } & & BDS & MDS & Chi- Square Value & P-Value \\
\hline \multirow{2}{*}{$\begin{array}{l}\text { 1. What other treatment } \\
\text { modalities are used for } \\
\text { caries removal }\end{array}$} & Air abrasion & $33 \%$ & $14 \%$ & 23.02 & 0.01 \\
\cline { 2 - 6 } & Sono abrasion & $14 \%$ & $15.5 \%$ & & \\
\cline { 2 - 6 } & CMCR & $6.5 \%$ & $10.50 \%$ & & \\
\cline { 2 - 6 } & Laser ablation & $2.5 \%$ & - & & $0.50 \%$ \\
\cline { 2 - 6 } & ART & $4.5 \%$ & $1.5 \%$ & & \\
\hline \multirow{2}{*}{$\begin{array}{l}\text { 2.What are the combination } \\
\text { of CMCR agent you know }\end{array}$} & $\begin{array}{c}\text { Cariodex and } \\
\text { Cariosolv }\end{array}$ & $9 \%$ & 14.36 & \\
\cline { 2 - 6 } & \begin{tabular}{c} 
Cariosolv and \\
\cline { 2 - 6 }
\end{tabular} & $12 \%$ & $15 \%$ & & \\
\hline
\end{tabular}




\begin{tabular}{|c|c|c|c|c|c|}
\hline & Papcarine & & & & \\
\hline & $\begin{array}{l}\text { Cariodex and } \\
\text { Papcarin } \\
\text { None }\end{array}$ & $\begin{array}{l}2.5 \% \\
37 \%\end{array}$ & $\begin{array}{l}3.5 \% \\
19.5 \% \\
\end{array}$ & & \\
\hline \multirow{5}{*}{$\begin{array}{l}\text { 3. What do you think } \\
\text { would be the reason for } \\
\text { choosing the CMCR } \\
\text { system? }\end{array}$} & No need anesthesia & $9.5 \%$ & $4 \%$ & 30.47 & 0.01 \\
\hline & $\begin{array}{l}\text { Convenience for } \\
\text { disable patients }\end{array}$ & $9 \%$ & $11.5 \%$ & & \\
\hline & $\begin{array}{l}\text { Easy to control in } \\
\text { difficulty children }\end{array}$ & $17.5 \%$ & $18.5 \%$ & & \\
\hline & Minimally invasive & $7.5 \%$ & $10 \%$ & & \\
\hline & $\begin{array}{l}\text { Facilitate ease in } \\
\text { anxious patients }\end{array}$ & $17 \%$ & $0.05 \%$ & & \\
\hline \multirow{4}{*}{$\begin{array}{l}\text { 4. What do you think would } \\
\text { be the reason for not choosing } \\
\text { the CMCR system? }\end{array}$} & Expensive & $26.5 \%$ & $3.5 \%$ & 28.45 & 0.05 \\
\hline & Time consuming & $16.5 \%$ & $18.5 \%$ & & \\
\hline & $\begin{array}{c}\text { Not having enough } \\
\text { information }\end{array}$ & $10.5 \%$ & $9.5 \%$ & & \\
\hline & $\begin{array}{l}\text { Inadequate method/ } \\
\text { Technique sensitive }\end{array}$ & $7 \%$ & $8.5 \%$ & & \\
\hline
\end{tabular}

\section{CONCLUSION}

It was found that MDS graduates had significantly higher knowledge regarding the chemo mechanical agents but clinical usage was comparatively lesser.The curriculum plays an important role in chemo mechanical caries removal agent needs to be determined precisely and clearly. There is a need for further research with more participants on whether education is sufficient in this regard. Through these researches, deficiencies in the education system should be identified and necessary arrangements made.

Authors Contribution: Author1(Amanthi Ganapathi) Carried out the retrospective study by collecting the data and drafting the manuscript after performing the necessary statistical analysis.Author 2(Dr.Jayashri.P) aided in the conception of the topic,participated in the study design,statistical analysis and supervised the preparation of the manuscript and helped in study design and has coordinated in developing the manuscript.All the authors have equally contributed in developing this manuscript.

Conflict of Interest: None to declare.

\section{REFERENCES}

Baglar, S. and Avunduk, A. T. E. (2018) 'Evaluation of the Place of Chemo-Mechanical Caries Removal Method in Dental Education among Turkish Students', Pesquisa Brasileira em Odontopediatria e Clínica Integrada, pp. 1-8.

Balciuniene, I., Sabalaite, R. and Juskiene, I. (2005) 'Chemomechanical caries removal for children', Stomatologija / issued by public institution 'Odontologijos studija' ... [et al.], 7(2), pp. 40-44.

Banerjee, A. and Doméjean, S. (2013) ‘The Contemporary
Approach to Tooth Preservation: Minimum Intervention (MI) Caries Management in General Practice', Primary Dental Journal, pp. 30-37.

Banerjee, A., Watson, T. F. and Kidd, E. A. M. (2000) 'Dentine Caries: Take It or Leave It?', Dental Update, pp. 272-276..

Beeley, J. A., Yip, H. K. and Stevenson, A. G. (2000) 'Chemochemical caries removal: a review of the techniques and latest developments', British dental journal, 188(8), pp. 427-430.

ten Berge, M. et al. (1999) 'Behavioural and emotional problems in children referred to a centre for special dental care', Community dentistry and oral epidemiology, 27(3), pp. 181-186.

Bijle, M. N. A. et al. (2013) 'Awareness of dental surgeons in Pune and Mumbai, India, regarding chemomechanical caries removal system', The journal of contemporary dental practice, 14(1), pp. 96-99.

Bjorndal, L. and Kidd, E. A. M. (2005) 'The Treatment of Deep Dentine Caries Lesions', Dental Update, pp. 402-413.

Bussadori, S. K., Castro, L. C. and Galvão, A. C. (2006) 'Papain Gel: A New Chemo-Mechanical Caries Removal Agent', Journal of Clinical Pediatric Dentistry, pp. 115-119.

Corrêa, F. N. P. et al. (2007) 'Chemical versus conventional caries removal techniques in primary teeth: a microhardness study', The Journal of clinical pediatric dentistry, 31(3), pp. 187-192.

Corrêa, F. N. P. et al. (2008) 'Fluorescence of primary dentine after chemomechanical and conventional rotary excavation', European Archives of Paediatric Dentistry, pp. 126-129.

Frencken, J. E. et al. (2012) 'Minimal intervention dentistry for managing dental caries - a review', 
International Dental Journal, pp. 223-243.

Ganesh, M. and Parikh, D. (2011) 'Chemomechanical caries removal (CMCR) agents: Review and clinical application in primary teeth', Journal of dentistry and oral hygiene. Academic Journals, 3(3), pp. 34-45.

Inglehart, M. R. et al. (2007) 'Chemomechanical caries removal in children', The Journal of the American Dental Association, pp. 47-55.

Kavvadia, K. et al. (2004) 'Primary teeth caries removal using the Carisolv chemomechanical method: a clinical trial', Pediatric dentistry, 26(1), pp. 23-28.

Khatri, S. G. et al. (2019) 'Retention of moisture-tolerant fluoride-releasing sealant and amorphous calcium phosphate-containing sealant in 6-9-year-old children: A randomized controlled trial', Journal of the Indian Society of Pedodontics and Preventive Dentistry, 37(1), pp. 92-98.

Kidd, E. A. M. (2004) 'How “Clean” Must a Cavity Be before Restoration?', Caries Research, pp. 305-313..

Kotb, R. M. S. et al. (2009) 'Clinical evaluation of Papacarie in primary teeth', The Journal of clinical pediatric dentistry, 34(2), pp. 117-123.

Manchery, N. et al. (2019) 'Remineralization potential of dentifrice containing nanohydroxyapatite on artificial carious lesions of enamel: A comparative in vitro study', Dental research journal, 16(5), p. 310.

Munshi, A. K., Hegde, A. M. and Shetty, P. K. (2001) 'Clinical evaluation of Carisolv in the chemicomechanical removal of carious dentin', The Journal of clinical pediatric dentistry, 26(1), pp. 49-54.

Prabakar, J., John, J., Arumugham, I. M., Kumar, R. P. and Srisakthi, D. (2018) 'Comparative Evaluation of Retention, Cariostatic Effect and Discoloration of Conventional and Hydrophilic Sealants - A Single Blinded Randomized Split Mouth Clinical Trial', Contemporary clinical dentistry, 9(Suppl 2), pp. S233S239.

Prabakar, J., John, J., Arumugham, I. M., Kumar, R. P. and Sakthi, D. S. (2018a) 'Comparative Evaluation of the Viscosity and Length of Resin Tags of Conventional and Hydrophilic Pit and Fissure Sealants on Permanent Molars: An Study', Contemporary clinical dentistry, 9(3), pp. 388-394.

Prabakar, J., John, J., Arumugham, I. M., Kumar, R. P. and Sakthi, D. S. (2018b) 'Comparing the Effectiveness of Probiotic, Green Tea, and Chlorhexidine- and Fluoride-containing Dentifrices on Oral Microbial Flora: A Double-blind, Randomized Clinical Trial', Contemporary clinical dentistry, 9(4), pp. 560-569.

Ricketts, D. (2001) 'Management of the deep carious lesion and the vital pulp dentine complex', British Dental Journal, pp. 606-610.

Schwendicke, F. et al. (2013) 'Attitudes and Behaviour regarding Deep Dentin Caries Removal: A Survey among German Dentists', Caries Research, pp. 566-573..

Scrabeck, J. G. and List, G. M. (1989) 'The status of a chemomechanical caries removal system in dental education', Operative dentistry, 14(1), pp. 8-11. Shenoy, R. P., Salam, T. A. A. and Varghese, S. (2019) 'Prevalence and Clinical Parameters of Cervical Abrasion as a Function of Population, Age, Gender, and Toothbrushing Habits: A Systematic Review', World Journal of Dentistry, 10(6), pp. 470-480.

Tyas, M. J. et al. (2000) 'Minimal intervention dentistry - a review*', International Dental Journal, pp. 1-12.

Uskokovi囚, V. and Bertassoni, L. E. (2010) 'Nanotechnology in Dental Sciences: Moving towards a Finer Way of Doing Dentistry', Materials, pp. 1674-1691.

Vishnu Prasad, S. et al. (2018) 'Report on oral health status and treatment needs of 5-15 years old children with sensory deficits in Chennai, India', Special care in dentistry: official publication of the American Association of Hospital Dentists, the Academy of Dentistry for the Handicapped, and the American Society for Geriatric Dentistry, 38(1), pp. 58-59.

Wolff, M. S., Allen, K. and Kaim, J. (2007) 'A 100year journey from GV Black to minimal surgical intervention', The Compendium of continuing education in dentistry, 28(3), pp. 130-4; quiz 135, 152.

Balciuniene, I., Sabalaite, R. and Juskiene, I. (2005) 'Chemomechanical caries removal for children', Stomatologija / issued by public institution 'Odontologijos studija' ... [et al.], 7(2), pp. 40-44.

Banerjee, A. and Doméjean, S. (2013) 'The Contemporary Approach to Tooth Preservation: Minimum Intervention (MI) Caries Management in General Practice', Primary Dental Journal, pp. 30-37.

Banerjee, A., Watson, T. F. and Kidd, E. A. M. (2000) 'Dentine Caries: Take It or Leave It?', Dental Update, pp. 272-276.

Beeley, J. A., Yip, H. K. and Stevenson, A. G. (2000) 'Chemochemical caries removal: a review of the techniques and latest developments', British dental journal, 188(8), pp. 427-430.

ten Berge, M. et al. (1999) 'Behavioural and emotional problems in children referred to a centre for special dental care', Community dentistry and oral epidemiology, 27(3), pp. 181-186.

Bjorndal, L. and Kidd, E. A. M. (2005) 'The Treatment of Deep Dentine Caries Lesions', Dental Update, pp. 402-413.

Bussadori, S. K., Castro, L. C. and Galvão, A. C. (2006) 'Papain Gel: A New Chemo-Mechanical Caries Removal Agent', Journal of Clinical Pediatric Dentistry, pp. 115-119.

Corrêa, F. N. P. et al. (2007) 'Chemical versus conventional caries removal techniques in primary teeth: a microhardness study', The Journal of clinical pediatric dentistry, 31(3), pp. 187-192.

Corrêa, F. N. P. et al. (2008) 'Fluorescence of primary dentine after chemomechanical and conventional rotary excavation', European Archives of Paediatric Dentistry, pp. 126-129.

Frencken, J. E. et al. (2012) 'Minimal intervention 
dentistry for managing dental caries - a review', International Dental Journal, pp. 223-243.

Ganesh, M. and Parikh, D. (2011) 'Chemomechanical caries removal (CMCR) agents: Review and clinical application in primary teeth', Journal of dentistry and oral hygiene. Academic Journals, 3(3), pp. 34-45.

Inglehart, M. R. et al. (2007) 'Chemomechanical caries removal in children', The Journal of the American Dental Association, pp. 47-55.

Kavvadia, K. et al. (2004) 'Primary teeth caries removal using the Carisolv chemomechanical method: a clinical trial', Pediatric dentistry, 26(1), pp. 23-28.

Khatri, S. G. et al. (2019) 'Retention of moisture-tolerant fluoride-releasing sealant and amorphous calcium phosphate-containing sealant in 6-9-year-old children: A randomized controlled trial', Journal of the Indian Society of Pedodontics and Preventive Dentistry, 37(1), pp. 92-98.

Kidd, E. A. M. (2004) 'How “Clean” Must a Cavity Be before Restoration?', Caries Research, pp. 305-313.

Kotb, R. M. S. et al. (2009) 'Clinical evaluation of Papacarie in primary teeth', The Journal of clinical pediatric dentistry, 34(2), pp. 117-123.

Manchery, N. et al. (2019) 'Remineralization potential of dentifrice containing nanohydroxyapatite on artificial carious lesions of enamel: A comparative in vitro study', Dental research journal, 16(5), p. 310.

Munshi, A. K., Hegde, A. M. and Shetty, P. K. (2001) 'Clinical evaluation of Carisolv in the chemicomechanical removal of carious dentin', The Journal of clinical pediatric dentistry, 26(1), pp. 49-54.

Prabakar, J., John, J., Arumugham, I. M., Kumar, R. P. and Srisakthi, D. (2018) 'Comparative Evaluation of Retention, Cariostatic Effect and Discoloration of Conventional and Hydrophilic Sealants - A Single Blinded Randomized Split Mouth Clinical Trial', Contemporary clinical dentistry, 9(Suppl 2), pp. S233S239.

Prabakar, J., John, J., Arumugham, I. M., Kumar, R. P. and Sakthi, D. S. (2018a) 'Comparative Evaluation of the Viscosity and Length of Resin Tags of Conventional and Hydrophilic Pit and Fissure Sealants on Permanent Molars: An Study', Contemporary clinical dentistry, 9(3), pp. 388-394.

Prabakar, J., John, J., Arumugham, I. M., Kumar, R. P. and Sakthi, D. S. (2018b) 'Comparing the Effectiveness of Probiotic, Green Tea, and Chlorhexidine- and Fluoride-containing Dentifrices on Oral Microbial Flora: A Double-blind, Randomized Clinical Trial', Contemporary clinical dentistry, 9(4), pp. 560-569.

Ricketts, D. (2001) 'Management of the deep carious lesion and the vital pulp dentine complex', British Dental Journal, pp. 606-610.

Schwendicke, F. et al. (2013) 'Attitudes and Behaviour regarding Deep Dentin Caries Removal: A Survey among German Dentists', Caries Research, pp. 566-573.

Scrabeck, J. G. and List, G. M. (1989) 'The status of a chemomechanical caries removal system in dental education', Operative dentistry, 14(1), pp. 8-11.

Shenoy, R. P., Salam, T. A. A. and Varghese, S. (2019) 'Prevalence and Clinical Parameters of Cervical Abrasion as a Function of Population, Age, Gender, and Toothbrushing Habits: A Systematic Review', World Journal of Dentistry, 10(6), pp. 470-480.

Tyas, M. J. et al. (2000) 'Minimal intervention dentistry - a review*', International Dental Journal, pp. 1-12.

Uskokovi邓, V. and Bertassoni, L. E. (2010) 'Nanotechnology in Dental Sciences: Moving towards a Finer Way of Doing Dentistry', Materials, pp. 1674-1691.

Vishnu Prasad, S. et al. (2018) 'Report on oral health status and treatment needs of 5-15 years old children with sensory deficits in Chennai, India', Special care in dentistry: official publication of the American Association of Hospital Dentists, the Academy of Dentistry for the Handicapped, and the American Society for Geriatric Dentistry, 38(1), pp. 58-59.

Wolff, M. S., Allen, K. and Kaim, J. (2007) 'A 100year journey from GV Black to minimal surgical intervention', The Compendium of continuing education in dentistry, 28(3), pp. 130-4; quiz 135, 152. 